\title{
The Hypotheses of Absolute and Relative Risk Aversion : An Empirical Study Using Cross-Section Data
}

\author{
by George G. Szpiro *
}

\section{Introduction}

In the mid-1960's Pratt [1964] and Arrow [1965] independently introduced the notions of "absolute" and "relative" risk aversion. Using these concepts, Arrow expounded two hypotheses about investment behavior: (a) The richer a consumer becomes, the more willing is he to engage in small bets of fixed size ; (b) the richer a consumer becomes, the less willing is he to invest a constant proportion of his wealth in risky assets. He justifies the first, the Absolute Hypothesis, by appealing to everyday observation about risky bets. He bases his defense of the Relative Hypothesis on theoretical considerations and on its ability to explain observed economic behavior with respect to the holding of cash. (Selden [1956], Friedman [1959], Latane [1963], Meltzer [1963].)

The purpose of this paper is to test Arrow's hypotheses in the context of another class of riskless assets, i.e., insured goods. ${ }^{1}$ In Section 2 Arrow's hypotheses are "translated" into this medium; in Section 3 empirical evidence on the relationship of insurance expenditures to private consumption is presented in support of the two hypotheses and in Section 4 we shall relax an assumption that had to be made in Section 3.

This evidence, drawn from a cross-section of nearly thirty countries, not only supports the Relative Hypothesis, but even permits a somewhat stronger statement in

* Jerusalem School of Business Administration, The Hebrew University, Israel. The author would like to thank Professors Marshall Sarnat and David Levhari for many helpful discussions : they are, however, not to be held responsible for any remaining errors.

Thanks are also due to two anonymous referees whose insightful remarks led to a greatly improved paper.

The numerical data contained in this paper have been kindly provided by the Swiss Reinsurance Company, Zurich.

An earlier version of this paper was presented at the Erhardt Seminar at Tel-Aviv University.

1 In the Appendix it will be shown that the two hypotheses can be derived from assumptions about risk aversion, using insurance instead of symmetric bets and investment. 
terms of insured assets. On the other hand, only partial support is offered to the Absolute Hypothesis. ${ }^{2}$

\section{Arrow's hypotheses in the insurance context}

An individual's total assets, $A$, can be either insured or left uninsured and we can write

$$
A=V+I
$$

where $V$ and $I$ denote, respectively, the uninsured and the insured part of assets.

\subsection{The relative hypothesis}

Arrow's Relative Hypothesis states that relative risk aversion is an increasing function of wealth, which means, in his words, that " if both wealth and the size of the bet are increased in the same proportion, the willingness to accept the bet (as measured by the odds demanded) should decrease" (p. 36). From this it follows that "the wealth elasticity for the demand for cash balances is at least one" (p. 43) ${ }^{3}$.

For the purposes of this paper Arrow's risky bets become our uninsured assets, his riskless cash balances are translated as insured assets, and willingness to bet will be measured by the proportion of assets which are left uninsured.

\subsection{The absolute hypothesis}

According to Arrow, absolute risk aversion is a decreasing function of $A$ which means "that the willingness to engage in small bets of fixed size increases with wealth, in the sense that the odds demanded diminish" (p. 34). From this it follows that "the amount of risky investment increases with wealth" (p. 43).

In the insurance model Arrows' bets and risky investments again correspond to uninsured asset, wealth become total assets and the willingness to bet is measured as the amount of assets left uninsured.

2 Arrow's original hypotheses are set out in terms of consumers with different wealths; here we compare average consumers of different countries with different wealths. Clearly, there are other factors apart from wealth which determine insurance behavior: cultural differences, availability of insurance contracts, etc. However, they are not germane to this paper.

3 A proof that this last statement can be derived from the Relative Hypothesis in the insurance context as well, is given in the Appendix. 


\subsection{Implications for empirical tests}

Hence it follows from 2.1. that in an insurance context Arrow's Relative Hypothesis can be written as

$$
\frac{d(V / A)}{d A}<0
$$

From 2.2. we can see that the Absolute Hypothesis is equivalent to

$$
\frac{d V}{d A}>0
$$

\subsection{The model}

We shall now formulate a model which serves as a device for testing the predictions using flow rather than stock data.

Let us assume that a person works for $T$ years, earns a constant salary, and spends the same amount annually on personal consumption $(C) .{ }^{4}$ Assume further that personal consumption can be divided into current expenditures and asset accumulation and that they are constant over time, i.e., the consumer spends a fixed amount, $k$, of his personal consumption on durable goods. Thus at the end of his lifetime the consumer will own assets of the amount $A$,

$$
A=k C T
$$

and at any point in time the average person in a population will own $1 / 2 \mathrm{~A}$.

The average consumer spends an amount $N$ per year on non-life insurance premiums in order to insure assets of the amount $1 / 2 l$. The insurance premium reflects the yearly risk of loss as well as the loading demanded by the insurance companies to cover their expenses and profits. ${ }^{5}$ If we let $m$ be the insurance premium, we obtain

$$
1 / 2 \ln =N
$$

Substituting (1), (4), and (5) into (2) we derive the new requirement for the Relative Hypothesis :

$$
\frac{d(N / C)}{d C}>0
$$

In Section 3 below we shall show that the empirical evidence satisfies this requirement and even permits a somewhat stronger statement of the hypothesis.

4 This assumption, which corresponds to Friedman's permanent income hypothesis [1959] is quite reasonable in this context since in the empirical part we shall be looking at the average consumer; there we shall also discuss difficulties concerning the "average consumer".

5 Actually, non-life insurance includes more than just insurance for assets. However, it is very difficult to accurately separate asset insurance from all other insurance for most countries; therefore, we shall disregard this point for the time being but come back to it in Section 3. 
We now substitute (1) and (5) into (3) ; for Arrow's absolute hypothesis to hold, the following requirement must be satisfied :

$$
\frac{d N}{d C}<1 / 2 m k
$$
and $m$.

We shall see in Section 3 that this inequality does not hold for all values of $C$

\section{Empirical evidence}

For the empirical part it is assumed that each country's population is made up of average, i.e., representative consumers. Rubinstein [1974] states some conditions which are sufficient for this assumption to hold. ${ }^{6}$

For the moment we also assume that Purchasing Power Parity holds; this constraint will be relaxed in Section 4 .

To test the two hypotheses the annual per capita expenditures for non-life insurance in 29 countries are correlated with annual per capita personal consumption for each of the years 1971 and 1979. The countries for which data are available comprise 97 - 98 percent of non-life insurance expenditures of the western world in both years. Table 3 at the end of this paper summarizes the data. ${ }^{7}$

Clearly, the socio-economic characteristics and many other variables of these countries vary considerably. To correct, at least in part, for this mis-specification all regression functions are calculated twice: once for all countries in the sample and once for European countries alone in order to create a somewhat more homogenous subsample in terms of these characteristics.

The following regression equation is fitted to correlate $N / C$ with $C^{8}$ :

$$
N / C=a C+b C^{2}
$$

Figures $1 \mathrm{a}$ and $1 \mathrm{~b}$ show the results graphically for 1971 and 1979 ; the numerical results are given in Table 1 , with the $t$-statistics in parentheses. (Since we are only

6 Examples of such sufficient conditions are: (a) all consumers have utility functions of the exponential type and insurance exists against all possible risks; (b) all consumers have exponential utility functions and attach the same subjective probabilities to the probabilities of loss; (c) all consumers have non-exponential utility functions and attach the same subjective probabilities to the probability of loss and have the same "rate of patience" with respect to future consumption.

7 The insurance data in local currency are compiled every year by the Swiss Reinsurance Company from all the countries' annual reports on the insurance industry; the results are published in Sigma. For the purposes of this paper the data were converted into dollars using the average exchange rates of the year. Financial data and national accounting data were taken from the IMF's International Financial Statistics.

8 We must use homogenous regression functions (i.e., the constant term must be zero) since zero consumption implies that insurance expenditures vanish. 


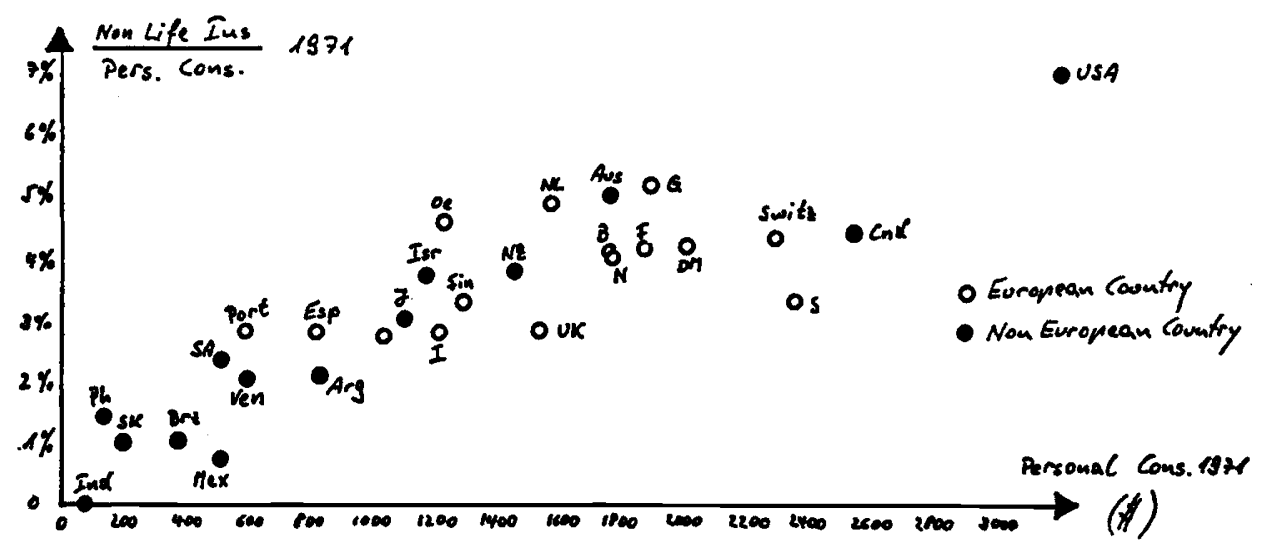

Figure 1 a

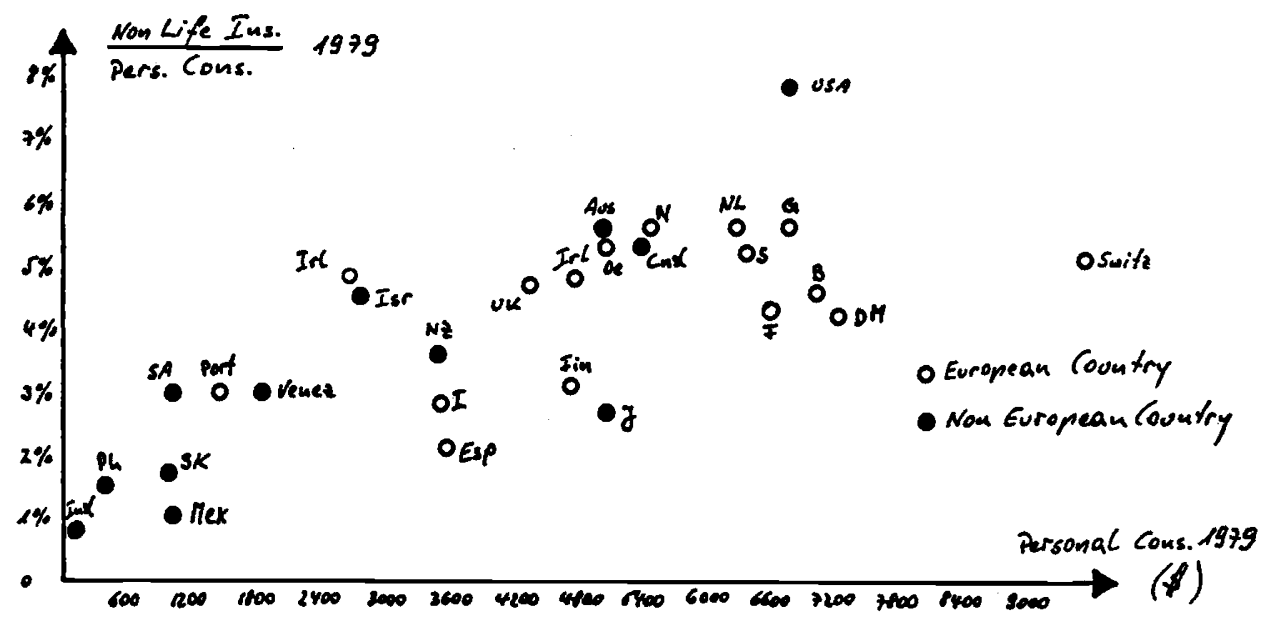

Figure $1 b$ 
testing for the sign of the coefficients we shall be using one-tailed tests.) ${ }^{9}$ As we noted in Section 2 the Relative Hypothesis required $d(N / C) / d C$ to be positive. Since $a$ is significantly greater than zero and $b$ is significantly smaller than zero (both at the $1 \%$ level) this is satisfied for all $C<C^{*}$ where

$$
C^{*}=-\frac{a}{2 b} \text {. }
$$

Hence Arrow's hypothesis is verified using insured and uninsured assets as proxies for riskless and risky assets whenever personal consumption is smaller than $C^{*} .10$

But an additional fact emerges : in all four cases the value of $b$ is significantly smaller than zero which implies that $d^{2}(N / C) d C^{2}<0$ which, in turn, implies that if both wealth and the size of the uninsured assets increase in the same proportion, the willingness to leave these assets uninsured should decrease at a decreasing rate which suggests that the elasticity of insurance is at least one, but diminishes with increasing wealth.

Table 1: Empirical evidence for the Relative Hypothesis

1971

a $\quad b \quad R s q$

$C^{*}$

Whole Sample

$+3.25(\mathrm{E}-5)$

-4.75 (E-9)

.766

3385

Size $=29$

Europe Only

$+4.28(\mathrm{E}-5)$

$-1.10(\mathrm{E}-8)$

.368

1945

$=15$

(4.1)

1979

Whole Sample

$=27$

$+1.45(\mathrm{E}-5)$

-9.95 (E-10)

.578

7323

Europe Only

$=15$

$$
+1.35(\mathrm{E}-5)
$$

.234

7500

To correlate $N$ with $C$ the following regression function is fitted to the data:

(9)

$$
N=r C+s C^{2}
$$

Figures 2 a and $2 \mathrm{~b}$ show the graphical results for 1971 and 1979 ; the numerical results are given in Table 2 .

9 The relatively low values of the coefficients of determination $(R s q)$ need be of little concern, since we are not dealing here with the goodness of fit of the regression functions : the test of the hypotheses' validity lies in the signs of the regression coefficients and their significance level. In all twelve cases examined here the requirements are satisfied (Table $1-3$ ).

10 Actually, the regression functions suggest that at levels of $C$ as high as Switzerland's (1971 and 1979) or Sweden's (1971) the Relative Hypothesis may no longer hold. However, the evidence presented in this paper is not sufficiently strong to support this point. 


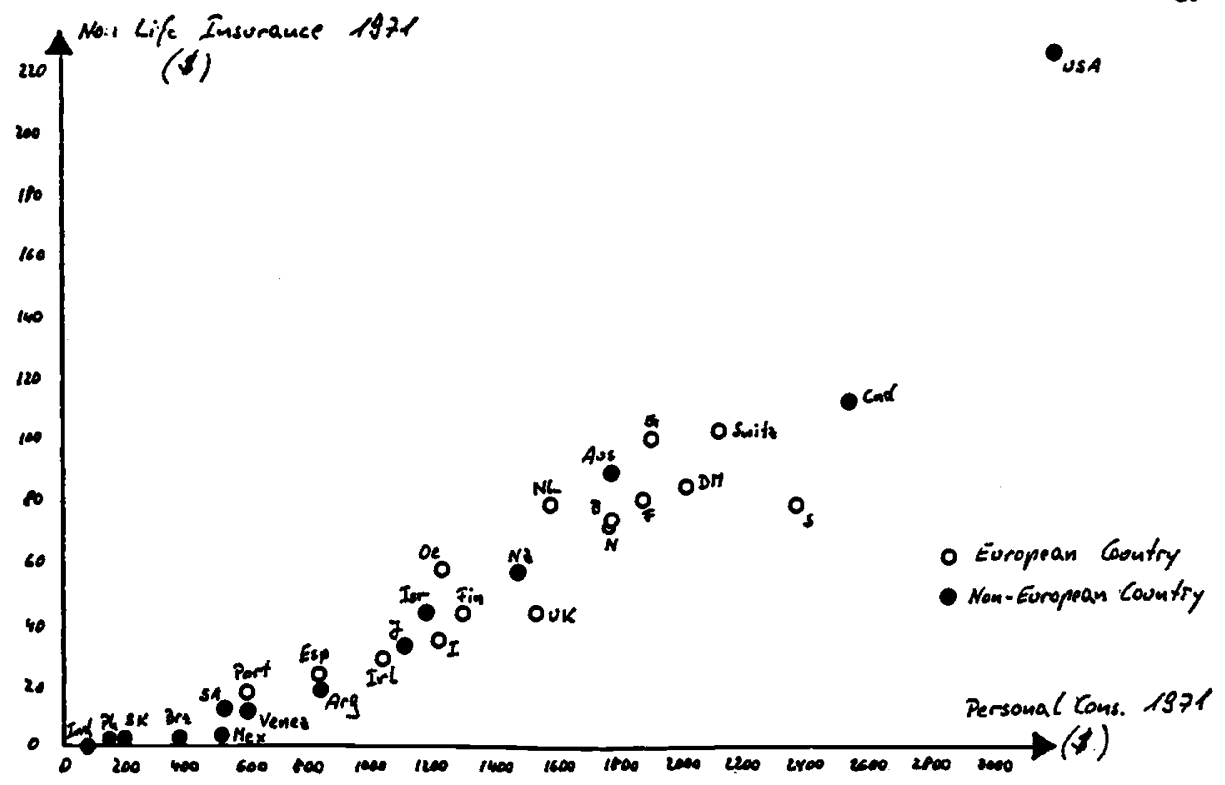

Figure $2 a$

Non Life Insurance 1979

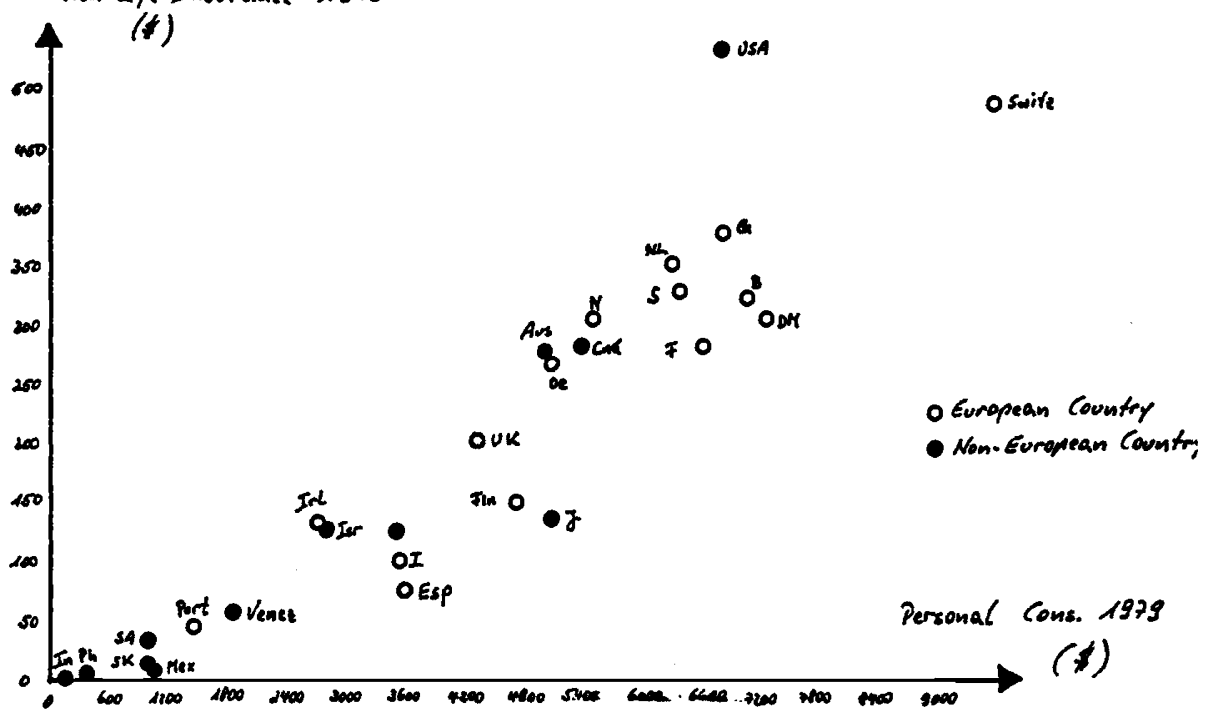

Figure $2 b$ 
Table 2: Empirical evidence for the absolute hypothesis

\begin{tabular}{|c|c|c|c|}
\hline \multirow{2}{*}{\multicolumn{4}{|c|}{1971}} \\
\hline & & & \\
\hline $\begin{array}{l}\text { Whole Sample } \\
\text { Size }=29\end{array}$ & $\begin{array}{l}+\frac{1.33(\mathrm{E}-2)}{(2.7)} \\
+{ }^{2}\end{array}$ & $\begin{aligned} &+ 1.51(\mathrm{E}-5) \\
&(6.7)\end{aligned}$ & .931 \\
\hline $\begin{array}{l}\text { Europe Only } \\
\quad=15\end{array}$ & $\begin{aligned}+ & 3.12(\mathrm{E}-2) \\
& (3.5)\end{aligned}$ & $\begin{array}{l}+4.65(\mathrm{E}-6) \\
(1.0)\end{array}$ & .810 \\
\hline \multicolumn{4}{|l|}{1979} \\
\hline $\begin{array}{l}\text { Whole Sample } \\
\quad=27\end{array}$ & $\begin{aligned}+ & 3.33(\mathrm{E}-2) \\
& (4.0)\end{aligned}$ & $\begin{array}{l}+2.46(\mathrm{E}-6) \\
(1.9)\end{array}$ & .861 \\
\hline $\begin{array}{l}\text { Europe Only } \\
\quad=15\end{array}$ & $\begin{array}{l}+3.50(\mathrm{E}-2) \\
(4.2)\end{array}$ & $+\underset{(1.6)}{1.88(\mathrm{E}-6)}$ & .873 \\
\hline
\end{tabular}

As mentioned in the previous section, condition (7) required $d N / d C<1 / 2 m k T$ in order to support Arrow's hypothesis. Substituting (9) into (6) we have the new requirement

$$
1 / 2 m k T>r+2 s C
$$

Since $s$ is greater than zero in all four cases (once at the $1 \%$ level, once at the $5 \%$ level, and once at the $10 \%$ level of significance) it is not obvious that condition (10) will be satisfied for all values of $C$ : given $m, k$, and $T$ one can find a critical value of $C$ above which (10) does not hold, or, alternatively, given $k$ and $T$, condition (10) will be satisfied for large values of $C$ only if $m$ is sufficiently large.

Let us look at the numerical values on the right-hand side of (10) for the largest observed values of $C$ in both years (the United States in 1971, and Switzerland in 1979) :

$$
\begin{aligned}
& 1 / 2 m k T_{71}>.1107 \\
& 1 / 2 m k T_{79}>.0813
\end{aligned}
$$

The proportion of $C$ spent on durable goods, $k$, was 15.2 percent in the United States in 1971, and about 11 percent in Switzerland in 1979. ${ }^{11}$ If we assume that the consumer's accumulation period $T$ is about 50 years, then the Absolute Hypothesis implies premium rates, $m$ (probability of loss plus loading, for all assets) of at least 2.9 and 3.0 percent respectively. These values may seem too high ; however, we must now take into account that non-life insurance, $N$, includes more than just asset insurance : after deducting accident, liability, health, and other non-asset insurance from $N$ we are left with about 42 and 40 percent for asset insurance, in the United States (1971) and Switzerland (1979). Thus average insurance rates have to exceed about 1.2 percent in the United States and in Switzerland for the Absolute Hypothesis to hold even for the

11 Survey of Current Business (USA), and author's estimate based on United Nations Yearbook (Switzerland). 
largest observed values of $C .{ }^{12}$ Clearly, values of this magnitude for insurance premium rates are not unreasonable.

\section{Relaxation of purchasing power parity}

In Section 3 we had mentioned that for our empirical analysis to be valid we must assume Purchasing Power Parity to hold. In this section we show the regression results for 1979 using as variables personal consumption and non life insurance premia weighted with a purchasing power index. ${ }^{13}$ Table 3 shows the results which confirm our previous findings : both for the whole sample as well as for European countries alone, the values are significantly positive for $a$ and negative for $b$ (at the $1 \%$ level) and positive for $s$ (though not at so high a level of significance).

Table 3: Relaxation of PPP

Relative Hypothesis

1979

$\begin{array}{lcccc}\text { Whole Sample } & +\underset{1.81(\mathrm{E}-5)}{ } & -1.41(\mathrm{E}-9) & .277 & 6418 \\ \begin{array}{l}\text { Size }=22 \\ \text { Europe Only } \\ \quad=14\end{array} & +\underset{(9.7)}{1.73(\mathrm{E}-5)} & -1.36(\mathrm{E}-9) & .205 & 6360 \\ & (9.6) & (5.0) & & \end{array}$

Absolute Hypothesis

1979

\begin{tabular}{|c|c|c|}
\hline $\begin{array}{l}\text { Whole Sample } \\
=22\end{array}$ & $\begin{aligned}+ & 3.94(\mathrm{E}-2) \\
& (4.9)\end{aligned}$ & $\begin{aligned} &+ 2.12(\mathrm{E}-6) \\
&(1.7)\end{aligned}$ \\
\hline $\begin{array}{c}\text { Europe Only } \\
=14\end{array}$ & $\begin{aligned}+ & 4.19(\mathrm{E}-2) \\
& (6.8)\end{aligned}$ & $\begin{aligned} &+ 1.13(\mathrm{E}-6) \\
&(1.2)\end{aligned}$ \\
\hline
\end{tabular}

12 Rewriting equation (6) we have $d$ (Asset Insurance)/dC $=q(d N / d C)<m k T / 2$, where $q$ is the proportion of non-life premiums spent on asset insurance, i.e., 42 and 40 percent in our cases.

13 The purchasing power data were collected and published by the Union Bank of Switzerland (Gutmann and Kruck [1979]). A basket of 100 goods and services weighted by consumer habits were used for computation. However, because cities are taken in this study to represent the country as a whole and because of general methodological problems concerning purchasing power comparisons, the results of Table 3 should be taken as indicative only. 


\section{Data base}

Annual expenditures, per capita in current US dollars

$\begin{array}{lrrrrr}\text { Argentina } & 840 & 18 & \text { n.a. } & 92 & 37 \\ \text { Australia } & 1773 & 89 & 5065 & 282 & 96 \\ \text { Austria } & 1230 & 57 & 5095 & 269 & 81 \\ \text { Belgium } & 1787 & 73 & 7073 & 323 & 83 \\ \text { Brazil } & 380 & 4 & \text { n.a. } & 16 & 34 \\ \text { Canada } & 2550 & 112 & 5421 & 286 & 97 \\ \text { Denmark } & 2019 & 84 & 7300 & 307 & 93 \\ \text { Finland } & 1296 & 43 & 4770 & 149 & 66 \\ \text { France } & 1878 & 79 & 6628 & 285 & 61 \\ \text { Germany - W } & 1906 & 99 & 6820 & 382 & 86 \\ \text { Great Britain } & 1543 & 43 & 4365 & 204 & 56 \\ \text { India * } & 79 & 0 & 128 & 1 & \text { n.a. } \\ \text { Ireland } & 1041 & 28 & 2740 & 132 & 62 \\ \text { Israel } & 1186 & 44 & 2866 & 128 & 38 \\ \text { Italy } & 1220 & 34 & 3571 & 100 & 60 \\ \text { Japan } & 1112 & 33 & 5100 & 138 & 45 \\ \text { Mexico } & 522 & 4 & 1090 & 11 & \text { n.a. } \\ \text { Netherlands } & 1583 & 78 & 6346 & 354 & 102 \\ \text { New Zealand * } & 1474 & 56 & 3529 & 127 & \text { n.a. } \\ \text { Norway } & 1778 & 71 & 5529 & 309 & 72 \\ \text { Philippines } & 146 & 2 & 408 & 6 & 15 \\ \text { Portugal } & 602 & 17 & 1487 & 45 & \text { n.a. } \\ \text { South Africa } & 525 & 12 & 1046 & 31 & 59 \\ \text { South Korea } & 203 & 2 & 995 & 16 & \text { n.a. } \\ \text { Spain } & 824 & 23 & 3616 & 76 & 54 \\ \text { Sweden } & 2377 & 78 & 6422 & 331 & 87 \\ \text { Switzerland } & 2329 & 103 & 9604 & 490 & 96 \\ \text { United States } & 3226 & 225 & 6849 & 535 & 107 \\ \text { Venezuela } & 602 & 12 & 1878 & 56 & 58\end{array}$

\section{* April-April}

Sources : - Swiss Reinsurance Company, Sigma

- International Monetary Fund, International Financial Statistics

- Gutmann and Kruck [1979] 


\section{Conclusion}

This paper tests Arrows' hypothesis on absolute and relative risk aversion. While Arrow cites studies concerning the demand for cash balances in support of the Relative Hypothesis, I used insured and uninsured assets as proxies for the investment in risky and riskless assets. The empirical evidence supports and, in fact, even permits a stronger restatement of the Relative Hypothesis.

The Absolute Hypothesis, in whose support Arrow cites everyday observation, has also been confirmed. However, the dependency of the Absolute Hypothesis on the value of $C$ suggests that if personal consumption in real terms continues to rise sufficiently in the future, the shape of the regression functions must continue to change as it has done from 1971 to 1979.

\section{Appendix}

In this Appendix I shall show that Arrow's results also hold when translated into an insurance context.

A.I In this subsection the intuitive significance of the notions of risk aversion will be explained.

Absolute Risk Aversion is defined as

$$
R_{a}(Y)=-\frac{U^{\prime \prime}(Y)}{U^{\prime}(Y)}
$$

and Relative Risk Aversion as

$$
R_{r}(Y)=-Y \frac{U^{\prime \prime}(Y)}{U^{\prime}(Y)}
$$

where $Y$ stands for wealth and $U(Y)$ is a monotonely increasing, twice differentiable utility function with $U^{\prime \prime}(Y)<0$.

Let a person have a utility function $U(Y)$ and own wealth $Y^{*}$. He is faced with a risk of losing part of his wealth $L$ with probability $(1-p)$ but can insure himself against such loss by paying a premium $h$. The question is, how high the probability of loss has to be in order to induce the person to pay the insurance premium $h$.

We introduce a new variable $k$ such that

$$
L=h+k
$$

and we let $Y$ be the person's wealth after having paid the insurance premium,

$$
Y=Y^{*}-h \text {. }
$$

Thus the person has to decide between wealth $Y$ with certainty, and $(Y+h)$ or $(Y-k)$ with probabilities $p$ and $(1-p)$ respectively. We now look for the probability of loss $(1-p)$ at which he would be indifferent between insuring or not :

$$
U(Y)=p U(Y+h)+(1-p) U(Y-k)
$$

By expanding the terms on the right-hand side into a Taylor series we get

$$
0=p U^{\prime}(Y) h+p\left(h^{2} / 2\right) U^{\prime \prime}(Y)-(1-p) k U^{\prime}(Y)+(1-p)\left(k^{2} / 2\right) U^{\prime \prime}(Y)
$$


After some manipulations, and using the definition of Absolute Risk Aversion, we have

$$
p=\frac{k}{L} \frac{1+(1 / 2) R_{a}(Y) k}{1-(1 / 2) R_{a}(Y)(L-2 k)}
$$

Therefore, if the probability that no loss occurs is greater than the right-hand side of (A-3) the person will not insure. The term in parentheses, which depends on $R_{a}(Y)$, is thus a measure of risk aversion.

Note that if $h=k$, that is if $L=2 k$, equation (A-3) is identical to Arrow's equation (6).

We now look at the case where the loss is a percentage of total wealth, say $n Y$; let the insurance premium be a percentage of potential loss, say $(1-q) n Y$.

Using the definition of Relative Risk Aversion, we receive

$$
p=q \frac{1+(1 / 2) R_{r}(Y) q n}{1-(1 / 2) R_{r}(Y)(n-2 q n)}
$$

Here also the term in parentheses is a measure of risk aversion. For $q=0.5$, this equation again coincides with Arrows' equation (7).

A.2 I shall now prove that decreasing risk aversion implies that the amount of uninsured assets increases with wealth.

A consumer's assets consist of two parts: the uninsured $(V)$ and the insured $(A-V)$. His end-of-period wealth $Y$ thus consists of the wealth at the beginning, $A$, minus the losses on the uninsured part of $A, V x$ (where $x$ is a random variable) minus $(A-V) m$, the insurance premium on the insured part of $A$, where $m$ is the insurance rate. After rearranging the terms, we can write

$$
Y=A(1-m)+V(m-x) \text {. }
$$

By taking the expected utility on both sides and differentiating with respect to $V$ we have, as a condition for the optimal size of uninsured assets as a function of wealth (A-4) $\quad E\left[U^{\prime}(Y)(m-x)\right]=0$.

By differentiating (A-4) with respect to $V$ and $A$ and dividing, we show the dependence of the optimal $V$ on wealth

$$
\frac{d V}{d A}=-\frac{E\left[U^{\prime \prime}(Y)(m-x)(1-\dot{m})\right]}{E\left[\left(U^{\prime \prime}(Y)(m-x)^{2}\right]\right.}
$$

We know that the denominator is negative since we are assuming risk aversion; thus $d V / d A$ will have the same sign as the numerator.

We now show that decreasing Absolute Risk Aversion implies that the numerator is positive. For $(m-x)>0$ we have :

$$
R_{a}(A(1-m)) \geqslant R_{a}(A(1-m)+V(m-x)) .
$$

By the definition of $R_{a}$ :

$$
U^{\prime \prime}(Y) \geqslant-R_{a}(A(1-m)) U^{\prime}(Y) .
$$

Multiplying both sides by $(m-x)(1-m)$, which is positive, we get

$$
U^{\prime \prime}(Y)(m-x)(1-m) \geqslant-R_{a}(A(1-m)) U^{\prime}(Y)(m-x)(1-m)
$$


One can easily check that the same inequality holds for $(m-x)<0$, and we take the expected value on both sides :

$$
E\left[U^{\prime \prime}(Y)(m-x)(1-m)\right] \geqslant-R_{a}[A(1-m)](1-m) E\left[U^{\prime}(Y)(m-x)\right]
$$

The expected value on the right-hand side is equal to zero by (A-4) and thus the left-hand side is positive, which by (A-5), proves that $d V \mid d A>0$.

A.3 By definition, the wealth elasticity of insurance can be written as

$$
\text { Elast }(A-V, A)=\frac{A}{A-V} \frac{d(A-V)}{d A}=\frac{A}{A-V}\left(1-\frac{d V}{d A}\right)
$$

where $A-V$ is the insured part of wealth.

Using (A-5), substracting one from both sides, and expanding, we have

$$
\text { Elast }(A-V, A)-1=\frac{V E\left[U^{\prime \prime}(Y)(m-x)^{2}\right]+A E\left[U^{\prime \prime}(Y)(m-x)(1-m)\right]}{(A-V) E\left[U^{\prime \prime}(Y)(m-x)^{2}\right]}
$$

$$
=\frac{E\left[U^{\prime \prime}(Y)(m-x) Y\right]}{(A-V) E\left[U^{\prime \prime}(Y)(m-x)^{2}\right]}
$$

We see that Elast $(A-V, A)$ will be greater than unity if the right-hand term of (A-6) is greater than zero ; since the denominator is again negative we need to show that

$$
E\left[U^{\prime \prime}(Y) Y(m-x)\right]<0
$$

It will be shown that this is a consequence of the hypothesis of increasing relative risk aversion. By this hypothesis we have

$$
R_{r}[A(1-m)+V(m-x)] \geqslant R_{r}[A(1-m)]
$$

for $(m-x)>0$. By the definition of $R_{r}$, we have

$$
U^{\prime \prime}(Y) Y \leqslant-R_{r}[A(1-m)] U^{\prime}(Y) \text {. }
$$

Multiply both sides with $(m-x)$ to get

$$
U^{\prime \prime}(Y) Y(m-x) \leqslant-R_{r}[A(1-m)] U^{\prime}(Y)(m-x) .
$$

The same inequality holds for $(m-x)<0$ and we can thus take the expected value on both sides :

$$
E\left[U^{\prime \prime}(Y) Y(m-x)\right] \leqslant-R_{r}\left[A(1-m) E\left[U^{\prime}(Y)(m-x)\right]\right] .
$$

By $(\mathrm{A}-4)$ the expected value on the right-hand side is equal to zero, which proves inequality (A-7).

\section{REFERENCES}

ARROW, K. J. [1965]: "The theory of risk aversion", in Aspects of the Theory of Risk Bearing, Helsinki.

BUNDESAMT FUR PRIVATVERSICHERUNGSWESEN [1979]: Die privaten Versicherungseinrichtungen in der Schweiz, Bern. 
FRIEDMAN, M. [1959] : "The demand for money : Some theoretical and empirical results", Journal of Political Economy, 67, 327-351.

GUTMANN, M., and KRUCK, A. [1979]: "Prices and earnings around the globe", Union Bank of Switzerland Publications, 69.

INTERNATIONAL MONETARY FUND : International Monetary Statistics, various issues.

LATANE, H. [1963] : "Income velocity and interest rates: A pragmatic approach", Review of Economics and Statistics, 42, 445-449.

MELTZER, A.H. [1963]: "The demand for money: The evidence from time series", Journal of Political Economy, 71, 219-246.

MOSSIN, J. [1968]: "Aspects of rational insurance purchasing", Journal of Political Economy, 76, 553-568.

PRATT, J.W. [1964] : "Risk aversion in the small and in the large", Econometrica, 32, 122-136.

RUBINSTEIN, M. [1974] : "An aggregation theorem for securities markets", Journal of Financial Economics, 225-244.

SELDEN, R. T. [1956] : "Monetary velocity in the United States", in Studies in the Quantity Theory of Money, M. Friedman (ed.), University of Chicago Press, Chicago, Ill.

SWISS REINSURANCE COMPANY : Sigma, various issues.

UNITED STATES, DEPARTMENT OF COMMERCE [1980]: Statistical Abstract of the United States, Washington D.C.

UNITED NATIONS : National Accounts Yearbook, various issues. 